\title{
Making Accessibility Visible: Visualizing Spatial Accessibility Through Multi-Dimensional Scaling Model
}

\author{
Orlando A. Sabogal ${ }^{1}$, Diego A. Escobar ${ }^{2} \&$ Daniel R. Oviedo ${ }^{3}$ \\ ${ }^{1}$ Universidad Tecnológica de Pereira. Grupo de Investigación SIRIUS. Pereira, Colombia \\ ${ }^{2}$ Universidad Nacional de Colombia, Sede Manizales, Departamento de Ingeniería Civil, Colombia. \\ ${ }^{3}$ University College London, Gower Street, London WC1E 6BT, United Kingdom \\ Correspondence: Diego A. Escobar, Universidad Nacional de Colombia, Sede Manizales, Departamento de \\ Ingeniería Civil, Colombia. Tel: 887-9300, ext. 50264. E-mail: daescobarga@unal.edu.co
}

Received: April 26, 2018

Accepted: May 2, 2018

Online Published: May 21, 2018

doi:10.5539/mas.v12n6p70

URL: https://doi.org/10.5539/mas.v12n6p70

The research is financed by Technological University of Pereira. SIRIUS Research Group.

\begin{abstract}
Accessibility has progressively claimed a central role in policy discourse and planning in the Global South. However, availability of approaches for its assessment is still limited in practice. Multidimensional Scaling (MDS) is a statistical tool aimed at explaining relations of distances, such as the analyzed in accessibility, through the construction of a new space of projections. That way, results are easily visualized and interpreted. Our research explores the use of MDS for the visualization of spatial accessibility. Taking the cities of Pereira and Dosquebradas, which belong to the Metropolitan Area of the Centre-West (MACW) of Colombia, we calculate the shortest path from each intersection to the rest assuming trips in motorized and non-motorized transport modes. This approach allows to visually re-configure the spatial distribution of intersections in the transport network, graphically representing accessibility levels for different zones in the metropolitan region of analysis. The use of MDS enables a more intuitive interpretation of accessibility and the exploration of underlying factors that can influence spatial inequalities, as well as to visualize changes generated by different transport and land-use interventions. Results allow to visualize the configuration of the two municipalities in the metropolitan area in an easily interpretable fashion, identifying areas with limited accessibility and establishing comparisons between mode choices. The tool seeks to contribute to better-informing transport policy and accessibility appraisals and identifying potential spatial inequalities in relation to transport in urban areas, which was tested in various forums with local decision-makers and non-specialists in Colombia.
\end{abstract}

Keywords: accessibility, visualization, MDS, transport policy, social exclusion, inequalities

\section{Introduction}

Accessibility assesses the ease of communication between different geographical areas, communities or activities using one or a variety of transport modes (Morris, Dumble, \& Wigan, 1979). It is a primary need not perceived which acts as a mean to reach activities that are necessary for human development (Halden, 2011) and has become a central idea in transport development and planning (Geurs \& Van Wee, 2004). As a concept, accessibility can be traced back to the second decade of the 20th century with early applications in research on location theory and regional economic planning (Batty, 2009). A classic definition of the concept (Hansen, 1959), interprets Accessibility as «... the potential of opportunities for interaction», which incorporates the relationships between land-use and population, mediated by transport networks and modes (Morris et al, 1979). Accessibility enables social groups to reach essential opportunities for their wellbeing such as healthcare, education, employment, and social connections (J.K. Stanley, Hensher, J.R. Stanley, \& Vella-Brodrick, 2011).

Geurs and van Wee (2004) identified four main interrelated components of accessibility (see Figure 1): land use, which makes reference to demand and supply of opportunities (Escobar, \& García, 2012; Escobar, García, \& Cadena, 2013; Escobar, García, \& Tolosa, 2013); transport, which takes into account the disutility involved in moving between origins and destinations in the process of reaching opportunities (Martinez \& Viegas, 2013); temporal, associated to individual and collective temporal constraints; and individual, which considers people's 
social, economic and cultural characteristics. This approach has become very influential into transport planning thinking and accessibility research. They also identified four types of accessibility measures: Infrastructure-based accessibility measures, location-based measures, person-based measures, and utility-based accessibility measures. Infrastructure-based accessibility measures are used to describe the functioning of the transport systems through simple indicators like speed on a road network or congestion. Location-based measures highlight distance or connectivity indicators such as average time between two locations and contour lines; in this group is also the potential accessibility model also known as the gravity model. Person-based measures "analyze accessibility from the viewpoint of individuals incorporating spatial and temporal constraints" (Geurs \& Van Wee, 2004). Finally, utility-based accessibility measures reflect economic thinking in accessibility. More recently, Páez et al. (2012) focused on the usefulness of accessibility and identified accessibility measures according to their normative and positive aspects. Where normative aspects reflect the expectation of analysis or policy makers while positive aspects reflect reality and actual experience of individuals (Páez et al., 2012).

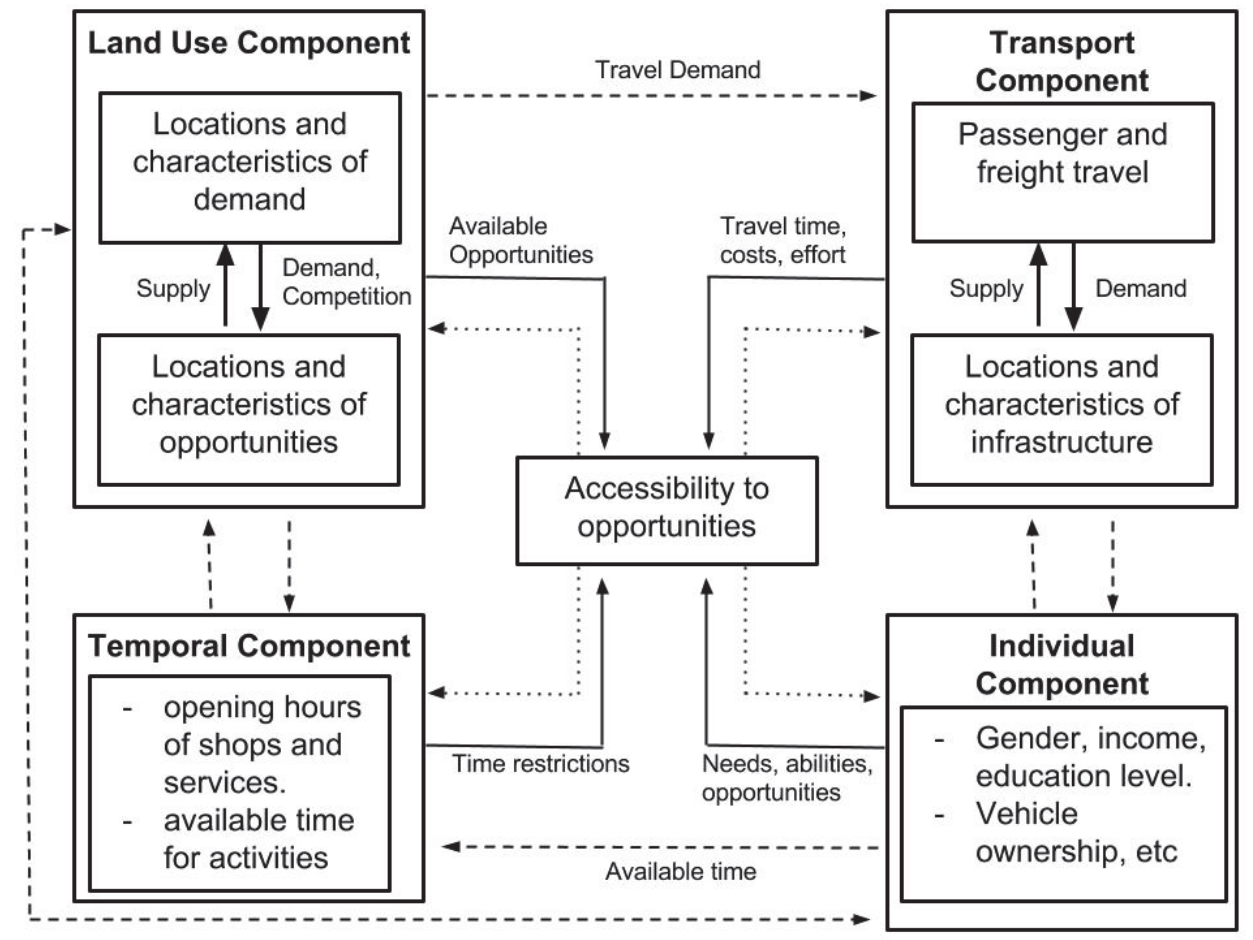

Figure 1. Four main components of accessibility and relationships among them as identified by Geurs and Van Wee (2004). Source: Based on Geurs and Van Wee (2004)

Even though accessibility is a widely-studied concept with a myriad of approaches, measures and taxonomies, it is still an active research topic with present gaps between theory and practice (Van Wee, 2016). Such is the case of the pictorial representation of accessibility levels, spatial phenomena and processes (Gutiérrez, CondecoMelhorado, \& Martín, 2010; Kotavaara, Antikainen, \& Rusanen, 2011; Muñoz, 2010), and their interpretation by policy makers and unspecialized audiences (Geurs, \& Van Wee, 2004; Páez et al., 2012; Lucas, Van Wee, \& Maat, 2015). This research fits into debates regarding accessibility and available methods for its analysis and visualization, emphasizing on easing the communication of accessibility metrics and analysis to non-specialists (Jones, \& Lucas, 2012), local communities, and decision-makers in second-tier cities of the Global South, enhancing participation and dialogue around transport planning. Our research contributes to current knowledge on accessibility measurement and visualization techniques.

MDS is a mathematical technique from multivariate statistics where the main input is a square distances matrix $(n * n)$ with elements $d \_i j$ representing the distance between object " $i "$ and object "j". Objects can be a set of persons, companies, or as in the case of this article, transport intersections within an urban area. The notion of distance is associated with the similarity or dissimilarity between those objects and can be conceptualized on the Euclidean tradition or as the result of a subjective appreciation. In this research the dissimilarity used is the shortest path among all intersections. MDS seeks to understand and explain the patterns of distances expressed in the matrix 
through the calculation of a coordinate system for the objects under analysis. MDS is a dimensional reduction algorithm for high-level matrices and the result is a display of the elements into a scatterplot. Distance is central in both MDS and accessibility analysis. While MDS aims at explaining distances, accessibility studies the spatial separation within urban areas and how it influences the ability of population groups to reach opportunities distributed in space. This is the starting point for linking MDS and accessibility.

The Metropolitan Area of Pereira and Dosquebradas - MAPD, is constituted by two second-tier cities in Colombia separated in their urban fringe only by the Otún River. Together they form one of the largest conurbation in the west-central region in the country (see Figure 2). Their location amidst the central branch of the Andes mountains (1,411 m.o.s.l) poses relevant spatial and physical challenges for urban development and spatial planning in an urban agglomeration that is expected to reach 700000 inhabitants by 2020 (Government of Pereira, 2016). However, despite clear proximity and spatial and functional conurbation between the two municipalities, their urban development policies and planning have been historically disconnected. As many other second-tier Colombian and Latin-American cities, Pereira and Dosquebradas haven't been extensively studied in international literature and there is limited information available, especially for accessibility models. Pereira and Dosquebradas population have traditionally characterized by their migrant vocation, with an important wave of migrants in the 90 s and early 2000s to the United States, Spain and rest of Europe. That way, remittances from out of the country occupy an important spot in the earnings of low and middle-income families. In addition, it makes the local economy very sensitive to internationally crisis. Even though the economy in Pereira has grown more slowly than the rest of the country (Pérez, Valencia, González, \& Cardona, 2014), the Gini Index for Pereira (0.439 in 2015) is below the national mean ( 0.522 in 2015). The main difficulties the city face are unemployment, increased poverty, inequalities and lack of planned public space (Pérez et al., 2014).

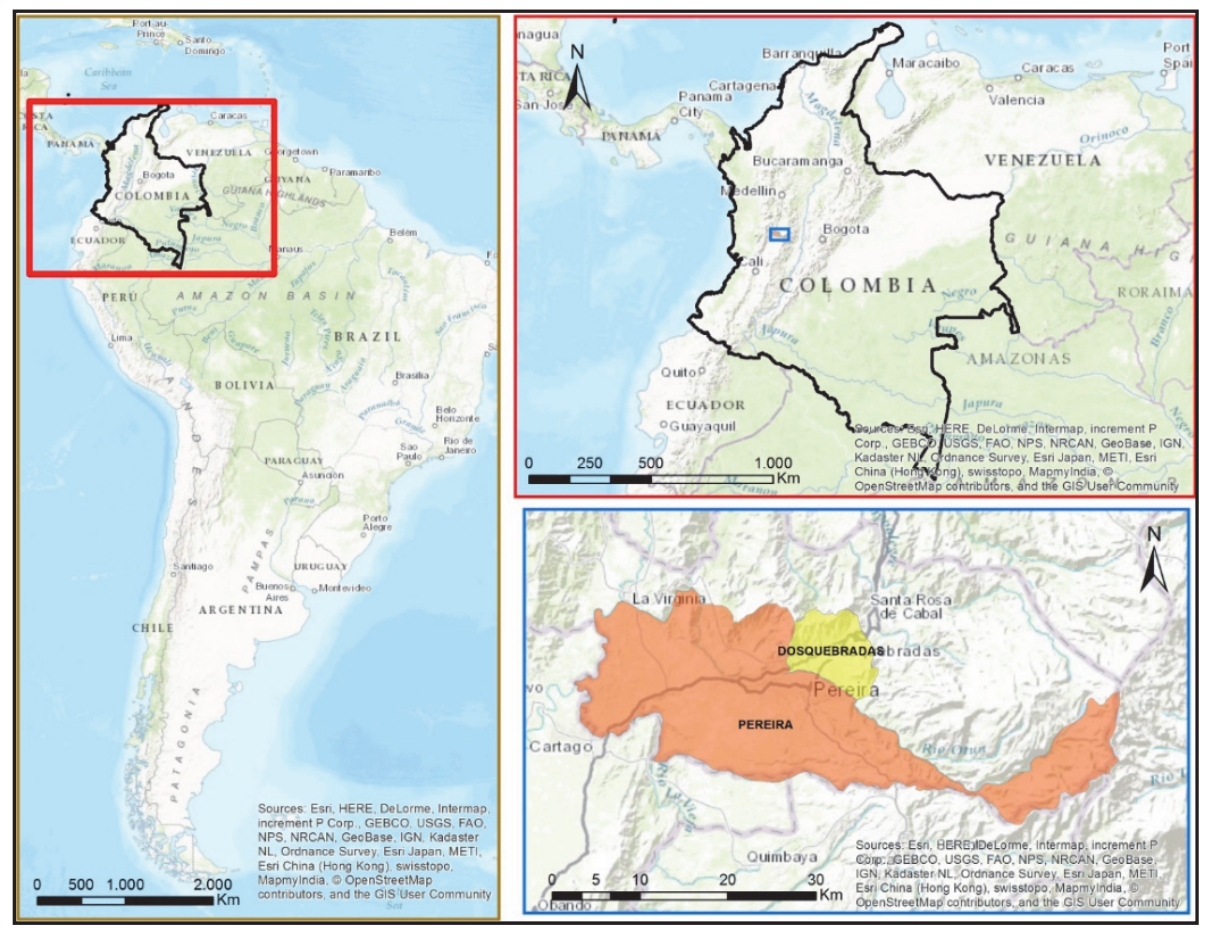

Figure 2. Study location. Source: Authors' own

The master plans for land-use and urban expansion in both cities lack cohesion, as each city follows independent planning processes without considerations at the larger metropolitan scale. Lack of metropolitan integration, institutional capacity, and regional cooperation lie at the core of a fragmented development of both cities, which have visible negative consequences on the levels of access to essential opportunities such as work and study in the region. From an accessibility perspective, it becomes then relevant to explore and quantify such processes, which suggests the potential need for alternative approaches to the visualization and analysis of spatial accessibility metrics. Despite this, Pereira and Dosquebradas are growing very fast. Table 1 shows household sales between 2013 and 2014. These sales have concentrated on middle and high income social groups and is necessary to incorporate accessible households to low stratums (Pereira Cómo Vamos, 2015). 
Table 1. Household sales in Pereira and Dosquebradas for 2013, 2014 and 2015

\begin{tabular}{ccccc}
\hline Year & Pereira & Dosquebradas & Total \\
\hline 2013 & 3009 & 1166 & 4175 \\
2014 & 3887 & 1256 & 5143 \\
2015 & 2529 & 2060 & 4589 \\
\hline
\end{tabular}

Source: CAMACOL 2015.

Especially because quantity household deficit has duplicated from 7\% to 14\% between 2011 and 2014 . Geographically, household has increased in the south side of the city and in a rural area in the west side; areas that as we will show later, have accessibility issues. On the other hand, as shown in Table 2, car and motorbike ownership in Pereira has drastically grown in the last 6 years, becoming more dependent from private vehicle. According to "Pereira Cómo Vamos" perception survey for 2015 most used transport modes were motorbike and urban buses (27\% each one) followed by Bus Rapid Transit systems (16\%), cars (11\%), walking (9\%), taxi (7\%), biking (2\%) and moto-taxi (1\%). The transport system in Pereira and Dosquebradas is governed by the private vehicle, particularly motorcycles, with a concentration of cars in the high income social groups. In addition, mean travel times are not evenly distributed. According to the origin-destination survey conducted in 2008, travel times were longer for the lower income groups. Stratum 6 has 21.79 minutes, stratum 5 has 26.8, stratum 4 has 28.66 minutes, stratum 3 has 30.8 minutes, and stratums 2 and 1 has 33.63 and 33.93 minutes, respectively.

Table 2. Cars growing by type from 2008 to 2014 in Pereira

\begin{tabular}{cccccccc} 
& $\mathbf{2 0 0 8}$ & $\mathbf{2 0 0 9}$ & $\mathbf{2 0 1 0}$ & $\mathbf{2 0 1 1}$ & $\mathbf{2 0 1 2}$ & $\mathbf{2 0 1 3}$ & $\mathbf{2 0 1 4}$ \\
\hline Cars & 34088 & 35388 & 37590 & 40424 & 43736 & 45845 & 50444 \\
Motorbikes & 41166 & 42592 & 43122 & 43946 & 47415 & 50800 & 59452 \\
Camper & 7363 & 7498 & 7830 & 8012 & 8272 & 8368 & 8629 \\
Van & 8228 & 8367 & 8663 & 9168 & 9751 & 10308 & 11922 \\
minibus & 594 & 597 & 601 & 605 & 621 & 634 & 670 \\
Buseta & 542 & 501 & 500 & 488 & 487 & 484 & 486 \\
Bus & 532 & 508 & 516 & 515 & 530 & 535 & 548 \\
Truck & 1616 & 1622 & 1671 & 1706 & 1840 & 1916 & 2043 \\
Turntable & 484 & 494 & 480 & 489 & 507 & 515 & 534 \\
Truck Tract & 163 & 161 & 158 & 158 & 166 & 167 & 182 \\
Farm Equipment & 22 & 19 & 19 & 21 & 21 & 20 & 20 \\
Others & 232 & 367 & 395 & 408 & 458 & 550 & 1100 \\
\hline Total & 95030 & 98114 & 101545 & 105940 & 113804 & 120142 & 136030 \\
\hline
\end{tabular}

Source: Authors' own based in Municipal Institute of Traffic of Pereira.

Building on the case of Pereira and Dosquebradas (Colombia), we use MDS to visualize spatial accessibility informed by distance matrices from a transport network. MDS produces a new spatial distribution of the intersection in the transport network that allows visual identification of accessibility levels to and from areas of interest, analysis of accessibility features of the network, and analysis of policy scenarios. Our research produces evidence-based contributions to: (i) approaches to diagnosing and assessing spatial accessibility through the application of MDS; (ii) visualizing and interpreting transport-related issues in urban and regional planning in intermediate cities in the global south; (iii) applying accessibility analysis beyond traditional analysis of work opportunities and services; and (iv) making accessible results from technical assessments to decision makers, practitioners in other disciplines and the general public. The development of technical tools that can make accessibility analysis more intuitive can support increased representation and empowerment of stakeholders in 
transport policy decision-making. This has been put to the test at different forums where non-specialist stakeholders in the two cities of analysis and other second-tier cities in Colombia have been familiarized with the methodology and results and provided feedback for the dissemination and use of MDS by practitioners.

After brief introduction, the research methodology is addressed, the main results obtained and the discussion and conclusions are presented. Finally, the references that support the proposed methodology are listed.

\section{Methodology}

The methodology relies heavily on open-source data. Geographic information of transport infrastructure facilities was obtained from free open sources. MDS calculations between all nodes (intersections) in the network are made for both, motorized and non-motorized transport. After having MDS rotated points, we pass to the visualization of main results and interpretation. Figure 3 shows the main stages of the methodology.

\subsection{Data Acquisition and Processing}

A primary input for the analysis is a geographic vector file representing the city's road network with streets lengths and directions, turns, intersections and other transport infrastructure features. Initial network information was obtained from OpenStreetMaps, a collaborative project to gather geographic and open information worldwide through crowdsourcing. Using QGIS connection to OSM we downloaded a preliminary geographic file hat covers an important share of the two cities (around 85\%). This information was compared and complemented with other sources such as Google Maps and Pereira's land use plan -"Plan de Ordenamiento Territorial"-. That way we overcame the remaining $15 \%$. Network information management and editing was carried out using open source software QGIS. Speed values (impedance) values were assigned to each link for both, motorized and nonmotorized modes. For motorized transport we use mean travel times based on the streets' functional speeds. That is, the speed values each street is supposed to have according to its design and type. For non-motorized transport we used distances (through the transport network). Slopes are not considered so no penalties are used. Hence, is importance to notice that using a walking or cycling speed value instead of distances would produce the same results.

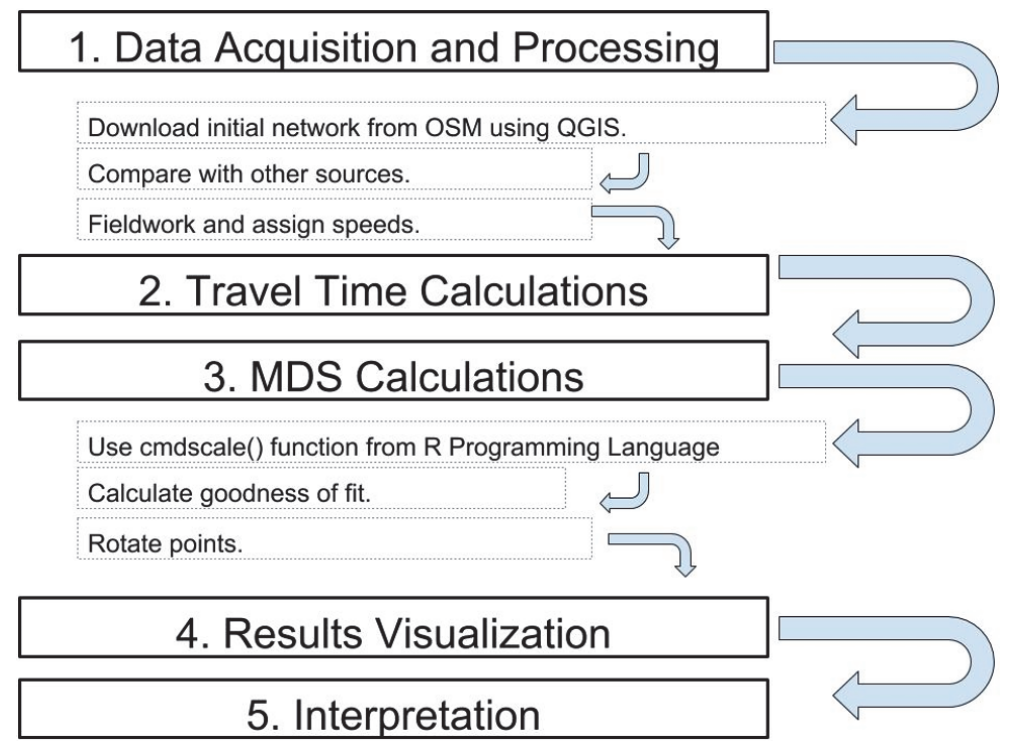

Figure 3. Research Methodology workflow. Source: Authors' own

\subsection{Travel Time Calculations}

Once the road network is complete, we calculate the shortest path from each of the "n" nodes in the network to the others " $n-1$ ". This is done for motorized and non-motorized transport modes. The result is an n square matrix B, the main input for MDS analysis. The calculation of the shortest paths among two nodes in a graph is an extensively studied problem and is incorporated in many commercial and free available software. The main option for make the calculations is the Dijkstra algorithm. Regardless computational tool employed it is necessarily to keep a link between coordinates points and its equivalent in square matrix B. This means knowing accurately every intersection location and its position in $\mathrm{B}$. 


\subsection{Multidimensional Scaling - MDS - Calculations and Points Rotation}

Multidimensional Scaling (MDS) is a mathematical method from multivariate statistics applied to matrices of distance for data reduction purposes. We have a group of " $\mathrm{n}$ " individuals or observations and a measure of similarity or dissimilarity between them. This means, there is a distance value $d_{-}$ij for each pair of individuals that can be arranged in a square (" $n * n ")$ matrix B where b_ii $=0$. For the purpose of this research observations are all the intersections in the transport network; the measures of dissimilarity are the travel times for motorized mode and distances on network for non-motorized mode. The main goal of multidimensional scaling is to plot information about how the observations (intersections) relate to each other. Its aim is to provide meaningful interpretation of the data (Rencher, 2012) and explains structures and patterns among observations not apparent from distances values (Everitt \& Hothorn, 2011). MDS is used to create a visual representation of the pattern of proximities among a set of objects or places.

Dissimilarities can be obtained in different ways and represent many concepts such as political affinity between senators according to how often they vote equal during a legislative period, contrasting results of academic or intellectual test to a group of students, psychological analysis or Euclidean computations. If we calculate distances or a similar measure between items, then the process of reduction to a lower dimensional geometric representation is called metric multidimensional scaling (Rencher, 2012), the used in this work. If the original distances are only similarities based on judgment, the process is called nonmetric multidimensional scaling (Rencher, 2012). MDS explains distances in B through a coordinate system $\mathrm{Y}$ (" $\mathrm{n} * \mathrm{t}$ ") where " $\mathrm{t}$ " corresponds to the coordinates projections and it is expected to be equal to 2 or 3 . If new distances $\delta \_i j$ are calculated from matrix $Y$ then $d_{-}\left[\mathrm{ij} \cong \delta \_\mathrm{ij}\right.$. These measures improve as more elements from " $\mathrm{t}$ " are retained, so there is a trade-off between the quality of the model and the number of dimensions in the projections to use. During the model fitting process (Torgerson, 1958; Kruskal, 1964; Borg \& Groenen, 2005; Everitt \& and Hothorn, 2011; Rencher, 2012) eigenvectors are calculated for each principal coordinate and a cumulative proportion of eigenvector is used to asses' model fit. Values above 0.7 for first two coordinates are considered as good. The quality of the models, meaning how good projections recover original variables, is near $73 \%$ for motorized transportation mode and above $85 \%$ for non-motorized transportation mode.

\subsection{Results Visualization}

Results consist on a set of indexed points with vertical and horizontal coordinates for three different spaces. All the elements in the first space have an element in the second and third space. First space has original nodes/intersections latitude and longitude locations while second and third spaces have MDS projections for motorized and non-motorized modes respectively. Intersections and group of intersections must be searched and highlighted in its initial locations and into the two other spaces as well. This allows seeing how points move and find its closer or nearest areas and, in abroad sense, helps to interpret spatial distribution and relations with the rest of the city. This is why knowing the position of the nodes in the squared matrices is so important. In section five we will present the results following the structure presented in Figure 5 where we located the initial geographic coordinates at the up left, the MDS result for motorized mode in the upright and the non-motorized MD result in the bottom.

\subsection{Interpretation}

Proposed accessibility analysis is based on visual interpretation of MDS projections compared to its geolocation and different aspects must be considered. Basic conclusions and initial analysis are taken from understanding city configuration within new spaces, identify central points, areas that are closer and areas that are far away from other points. Understanding of initial geographic information is necessary, as well as the distribution of opportunities and facilities. When comparing point's projections is vital to know socioeconomic characteristics of zones and bear in mind segregated neighborhoods and violence hotspots. Also, for an adequate interpretation it is necessary to identify areas with low connectivity and lack of infrastructure. This way analyst has elements for understand nodes spatial configuration in MDS projections. The analysis and visual results we will present explore the socioeconomic characteristics of population and the concentration of employment opportunities.

\section{Results and Discussion}

The main highway and transport infrastructure from the case study can be seen in Figure 4. Dosquebradas main highway is "Simón Bolívar" which goes through the city. Most important shopping centers, banks, companies and public offices are located over this highway. An alternative to Simón Bolívar is "La Variante" that also traverses the city and is characterized for having roundabouts that let commuters switch to Simón Bolívar, neighbourhoods around or going to "Variante El Pollo", a national highway with heavy truck traffic. On the other side, Pereira has more highways. The most important one is probably the " 30 de Agosto" that starts at the Risaralda Government 
building in "Olaya Herrera" park and crosses the rest of the city up to the end of the urban area. 30 de Agosto connects with "Ferrocarril" highway that links Pereira with Dosquebradas through "César Gaviria Trujillo" Viaduct (or "El Viaducto"). "De Las Americas" highway (Or "Sur") is also an important artery in Pereira that covers a considerably region. "Del Río" highway is in the fringe with Dosquebradas at the border of Otún River. Secondary highways are "Circunvalar", "Juan B. Gutierrez" and "Belalcazar". 14th street and 7th and 8th roads are the responsible for make traffic flow in the CBD. Figure 4 illustrates too the zones that did not exist in 2005 and expansions areas in Pereira. Standard intersections (nodes) longitude and latitude locations are presented in Figure 5 and to get context from the cities it can be complemented looking at the transport facilities presented in Figure 4. Results for both, motorized and non-motorized transportation modes Multidimensional Scaling model, can be seen in Figure 6a and Figure 6b, respectively.

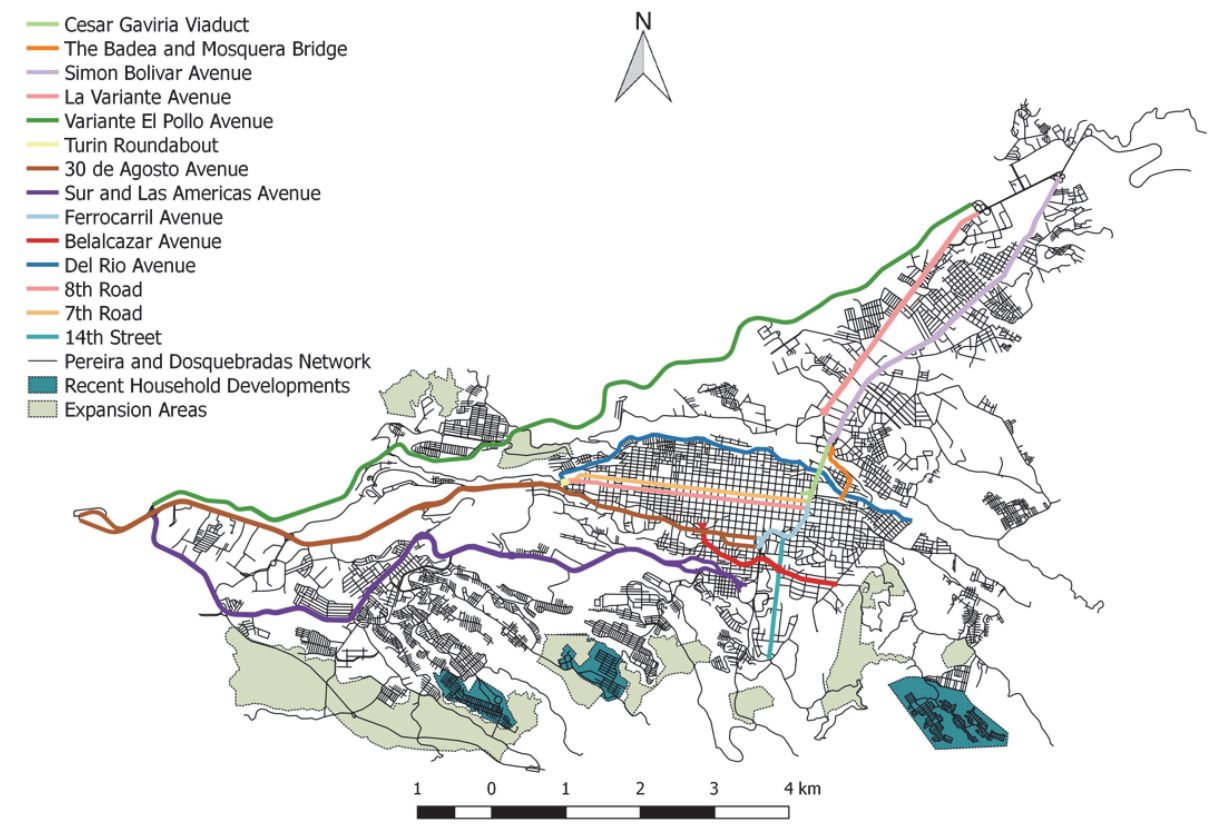

Figure 4. Pereira and Dosquebradas main transport facilities, and Pereira expansion and development areas

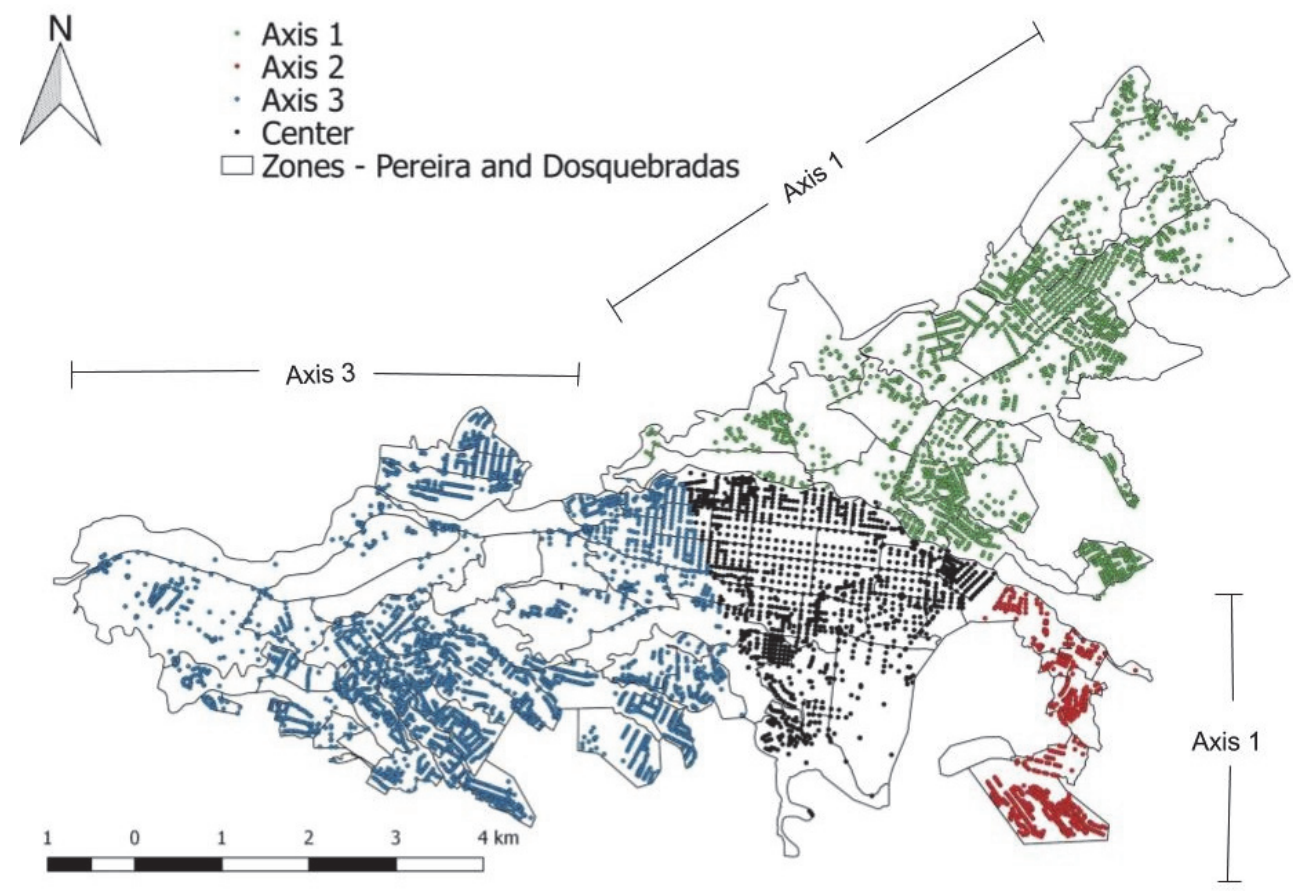

Figure 5. Standard intersections (nodes) longitude and latitude locations 
- MDS Projections - Axis 1

- MDS Projections - Axis 2

- MDS Projections - Axis 3

- MDS Projections - Center

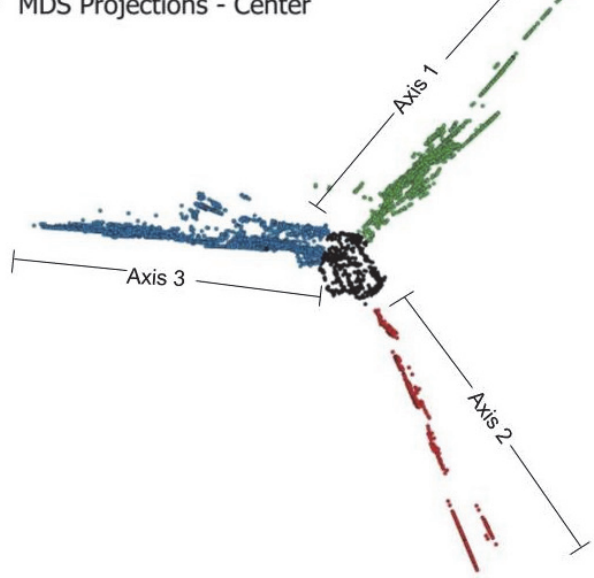

- MDS Projections - Axis 1

MDS Projections - Axis 2

- MDS Projections - Axis 3

- MDS Projections - Center

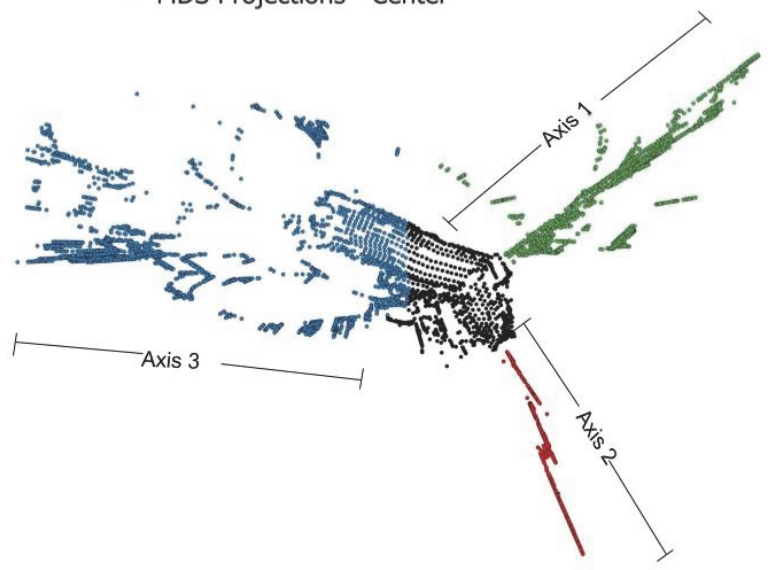

a) b)

Figure 6. Main results from MDS projections for transport mode: a) motorized; b) non-motorized

Although it is important to notice that configuration for motorized mode is more compact than for non-motorized, the two point projections can be grouped into four elements: a composite centre and three axes or branches emerging from that centre. All Branches lengthen in a linear direction while tightening up in a perpendicular direction to their first. Branch number one has all Dosquebradas nodes, branch number two has the east Pereira zone and branch number three the western area. These four elements are the way MDS model represents spatial distribution of accessibility for both cities and is the key outcome current research was looking for. Analysis and discussions should focus on understand that structure and its implications, decode the reasons behind it and use all that insights to propose infrastructure facilities investments as well as develop informed public policy.

To achieve those goals, we contrast and put in context MDS model results with socioeconomic stratification (Figure 7 and Figure 8) and work trips attraction by zones (Figure 9 and Figure 10).

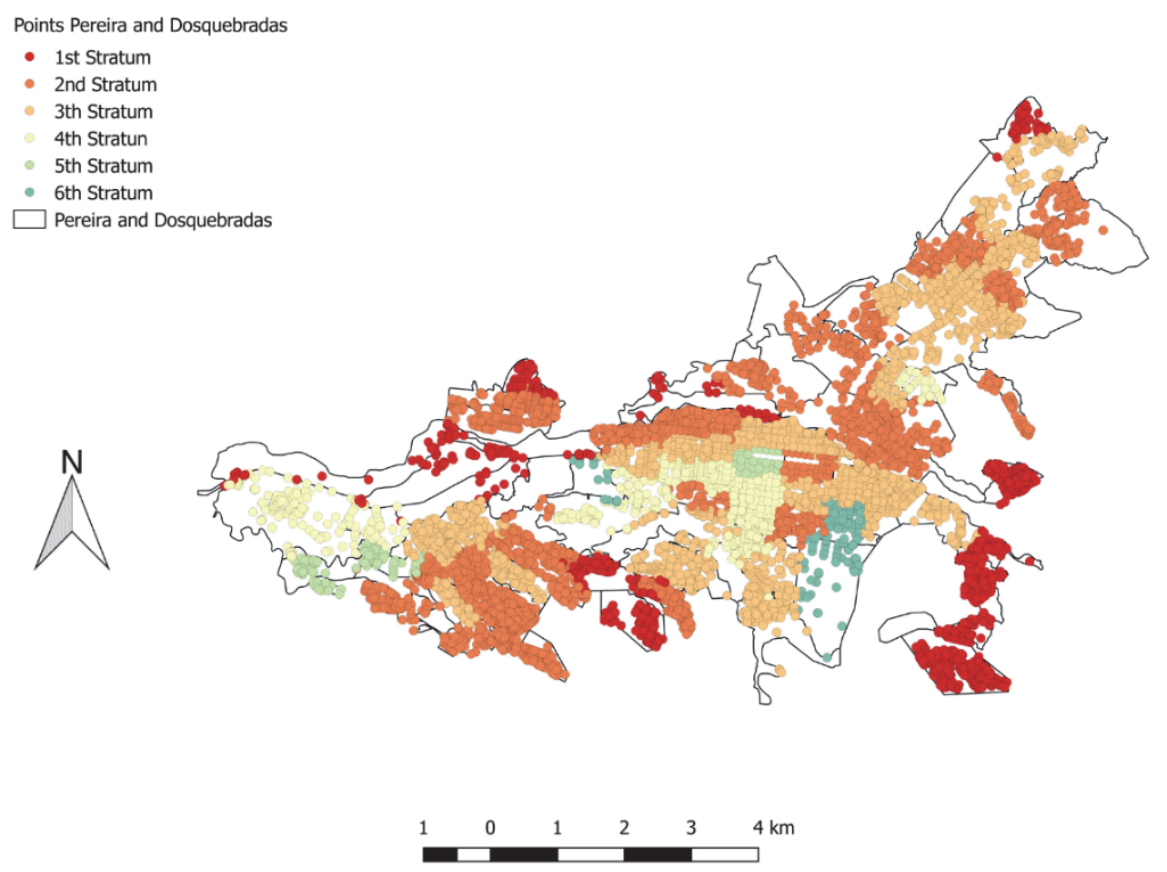

Figure 7. Stratum classification in Pereira and Dosquebradas 
Socioeconomic stratification in Colombia is a common proxy for purchasing power and levels of income, and it has been defined for the purpose of assigning fares for public utilities. In this classification, 1 is the lowest stratum, or the poorest, and 6 belongs to the highest-income group. The categorization of intersection in the analysis of accessibility using MDS by socioeconomic stratum is thus a first approach to the identification of socio-spatial inequalities in the Pereira-Dosquebradas metropolitan area.

As shown in Figure 8a and Figure 8b, lower income strata tend to be farther from the centre, evidencing poorer accessibility, particularly in the analysis by non-motorized modes. Middle-income groups tend to have better accessibility than even stratum 5 , which reflects the influence of suburban location for higher income groups and the socio-spatial distribution of the city that concentrates most of its middle class near the city centre. Interestingly, the highest income group, stratum 6, has the shortest distance to the centre in the MDS projections for both motorized and non-motorized modes, evidencing transport, urban and economic geographies that benefit those with higher resources to commute. Indeed, mean distance from all nodes in stratum 6 to the town hall of Pereira (located at the heart of the study area) is 1984.0 meters while for stratum 1 is 4316.2 meters. The longest mean distance is concentrated in stratum 5 with 5426.4 meters and for stratums 2, 3 and 4 is 3731.5 meters, 3313.7 meters and 3173.3 meters.

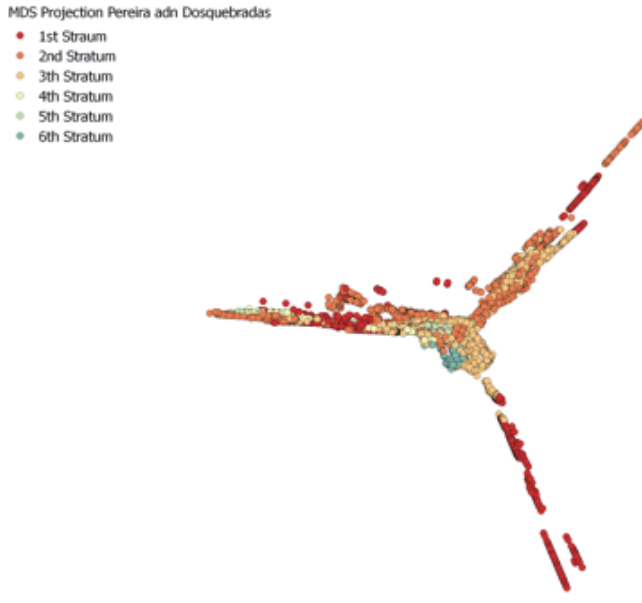

a)

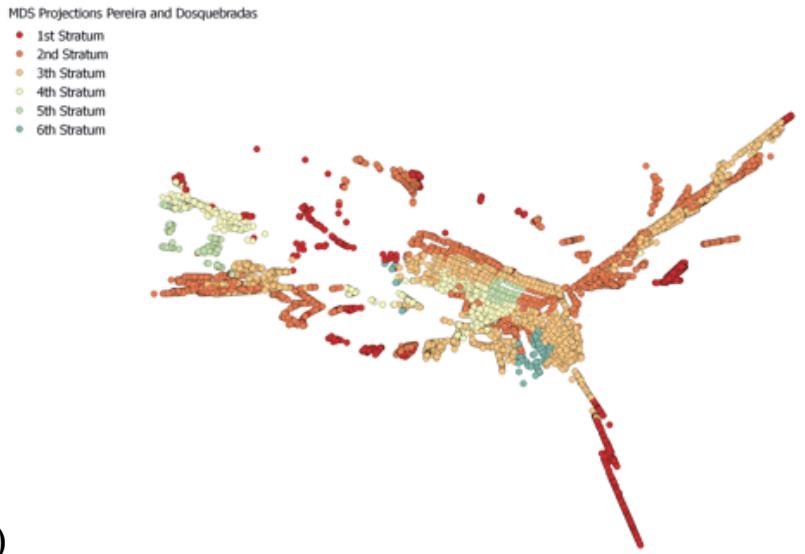

b)

Figure 8. MAPD nodes stratums on initial coordinates and MDS projections for transport modes: a) motorized;

b) non-motorized

In Figure 9 we present Pereira and Dosquebradas Traffic Analysis Zones (TAZs) where we have colored them per membership to work trips attraction quartiles, each quartile attracts $25 \%$ of total trip works. The first quartile encompasses only one central area that in projections is also part of the central area, and around it there are many other areas that also attracts a considerable amount of work trips, which means that most of the working opportunities are well located with good accessibility (See Figure 10a and Figure 10b). When compared to Figure 4 , it becomes clear that Pereira has been growing far away for main working post generators.

Central Area (black ring in Figure 5) has points with best accessibility because in average they are closest to all other nodes. It embraces classical Pereira center and high-income neighbourhoods Alamos and Pinares (see purple area in Figure 11). No points from Dosquebradas are included. An expected result is getting the central city area into the central MDS projections, but is striking that Alamos and Pinares make part too. Particularly because other zones with similar geographic distances to the center of the city are not included. As noticed in Figure 4 these neighbourhoods are enveloped by good transport infrastructure and it is easy to get from there to the main Avenues. Dosquebradas (branch one) itself doesn't has a consolidated interior area space. On the contrary, stretches toward main highways limiting with previously mentioned center and starting from a clear infrastructure characteristic: connectivity with Pereira through El Viaducto and Mosquera Bridge. A standard trip between Pereira and Dosquebradas includes pass through any of these facilities, so it makes sense an ordering related with distance to them. In a general perspective, these results are indicating that there is a connectivity problem between Pereira and Dosquebradas and that transport facilities are not enough. The fact that Dosquebradas itself as a city doesn't have a center in the model and that no one of its points are located in the center suggest that road network structure has been mainly designed to reach opportunities in Pereira. As displayed in Figure 11, a rural structure from Dosquebradas is penalised by MDS model. This area, called Frayles, is apparently near to the central and eastern 
Pereira points but it should be noticed that there is a geographic constraint imposed by Otún River (runs parallel to Del Rio Avenue) and altitude differences (Frayles and Dosquebradas are higher than Pereira). Additionally, there is not a direct transport connection between Frayles and Kennedy or Villa Santana. These characteristics are encapsulated by model and projections are located far away from Pereira central area (See Figure 12a and Figure 12b).

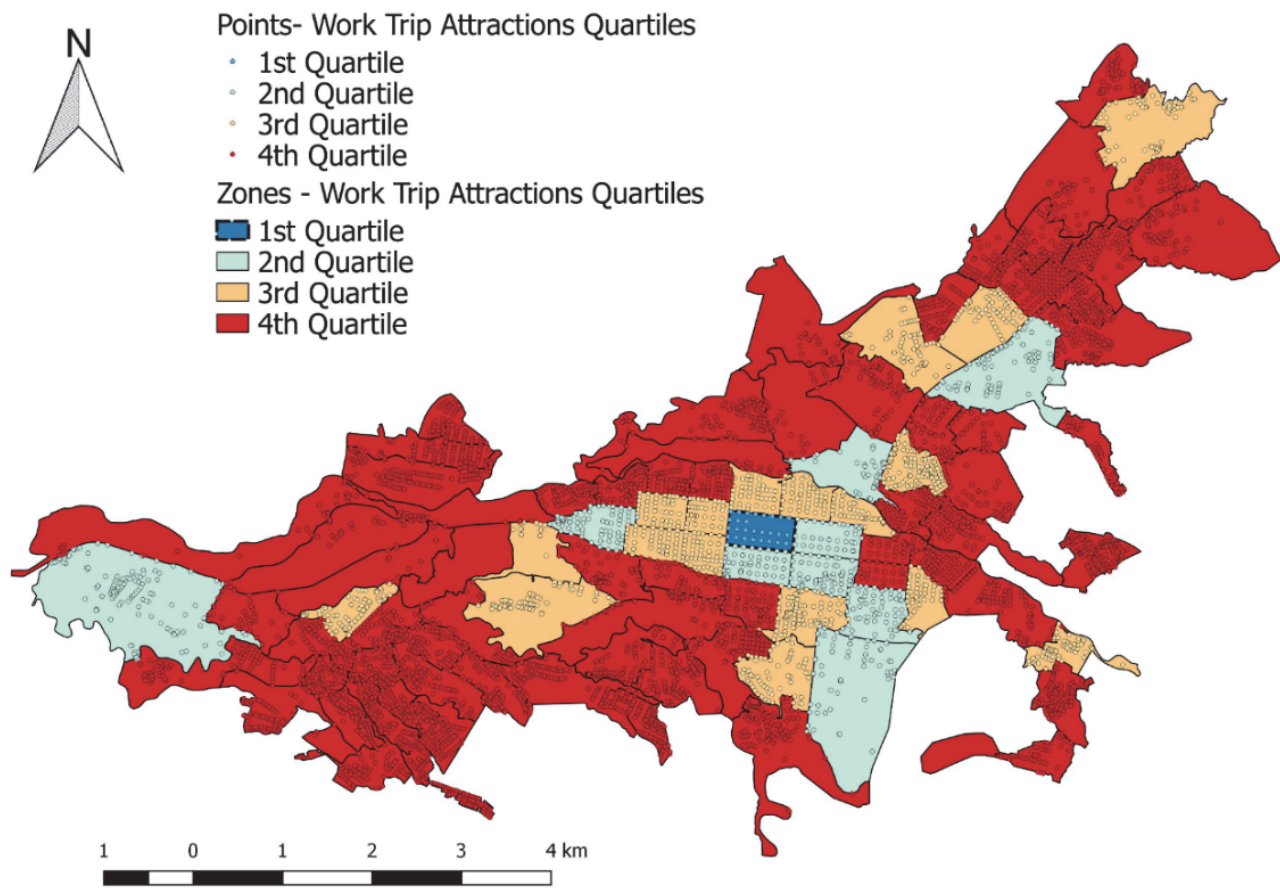

Figure 9. Work Trips Attraction
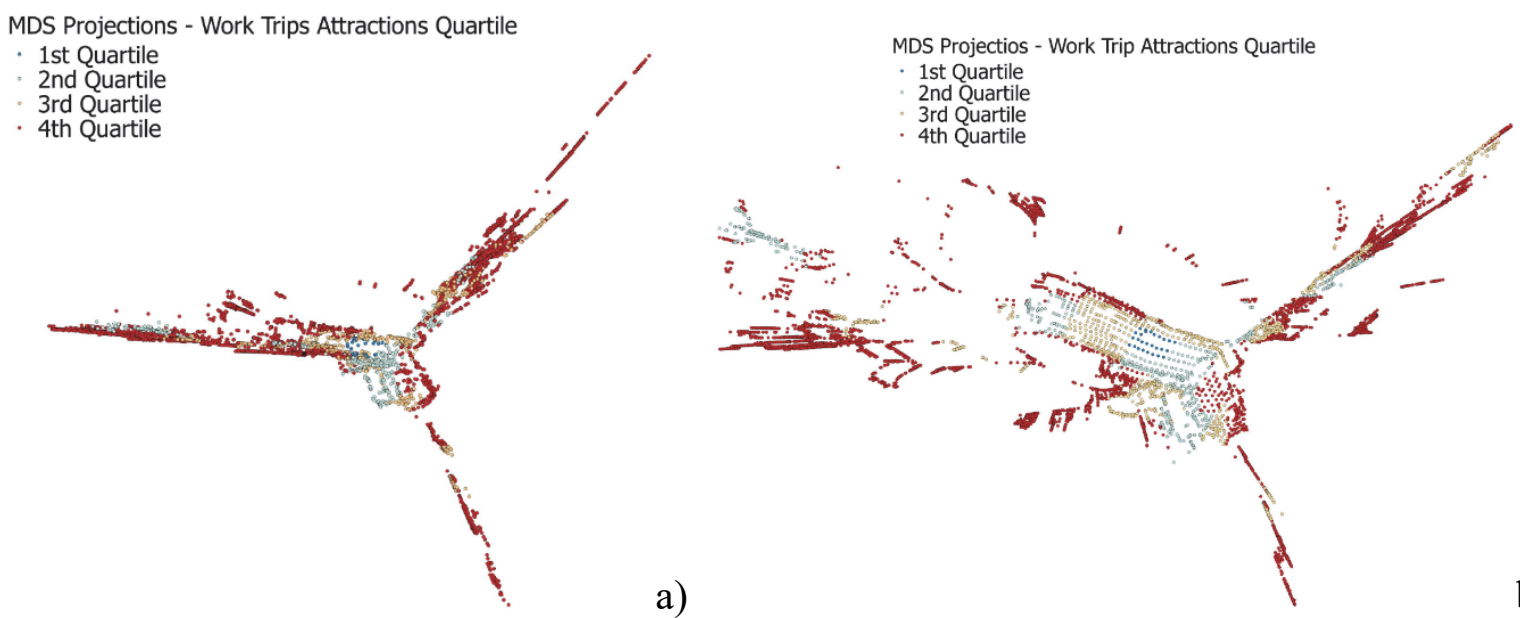

Figure 10. Work Trips Attraction and MDS projections for transport mode: a) motorized; b) non-motorized

Branch number two appears to have the most inaccessible zones in Pereira. In Figure 11 are shown Villa Santana, Tokio and El Remanso neighborhoods (they conform the Villa Santana Commune) on its original geographic locations and on its MDS principal coordinates. Visual interpretation leads to consider this as a segregated space in the city. In a similar Dosquebradas process, axes 2 also stretch in a direction and narrow perpendicular to it. As we go deeper into Villa Santana commune neighborhoods its equivalents points in MDS motorized projection (See Figure 12a) appears aloof the main branch axis. Model isolate this area that is identified as a problematic sector with poverty and inequities issues, lack of transport infrastructures, health and academic facilities, local and 
national government absence, drugs traffic and war groups presence. It is also one of the growing areas in Pereira because of migration processes from war displacement in rural areas. As shown in Figure 4 this is an area that has grown in lately years. Comparing Pinares and Alamos commune with Villa Santana commune is contrast one of the richest and welfare zones with one of the poorest zones where former enjoys best accessibility while second has worst accessibility. Despite these differences both zones are separated only by a reserve and risky zone (According to "Plan de Ordenamiento Territorial Pereira 2015 - 2027", see orange polygon in Figure 11) where "Cacerío Canceles" is located. Another particularity is that Pinares and Alamos have only the $2.17 \%$ of the total kilometers of the study area (near $18962.34 \mathrm{Km}$ out of $875369.3 \mathrm{Km}$ ) while Villa Santana commune have $4.86 \%$ (42 559.41 Km), nevertheless and despite that these two areas are not highly geographically separated, the former has considerably more accessibility. Hence, it makes sense to assert that facilities in high income neighborhoods are more efficient. An action to improve Villa Santana Commune situation is improving its connectivity with the rest of the city, so public policy in for coming year should arrest this affair. Villa Santana commune situation is an evidence of inequalities associated to transportation and land cost correlation with accessibility.

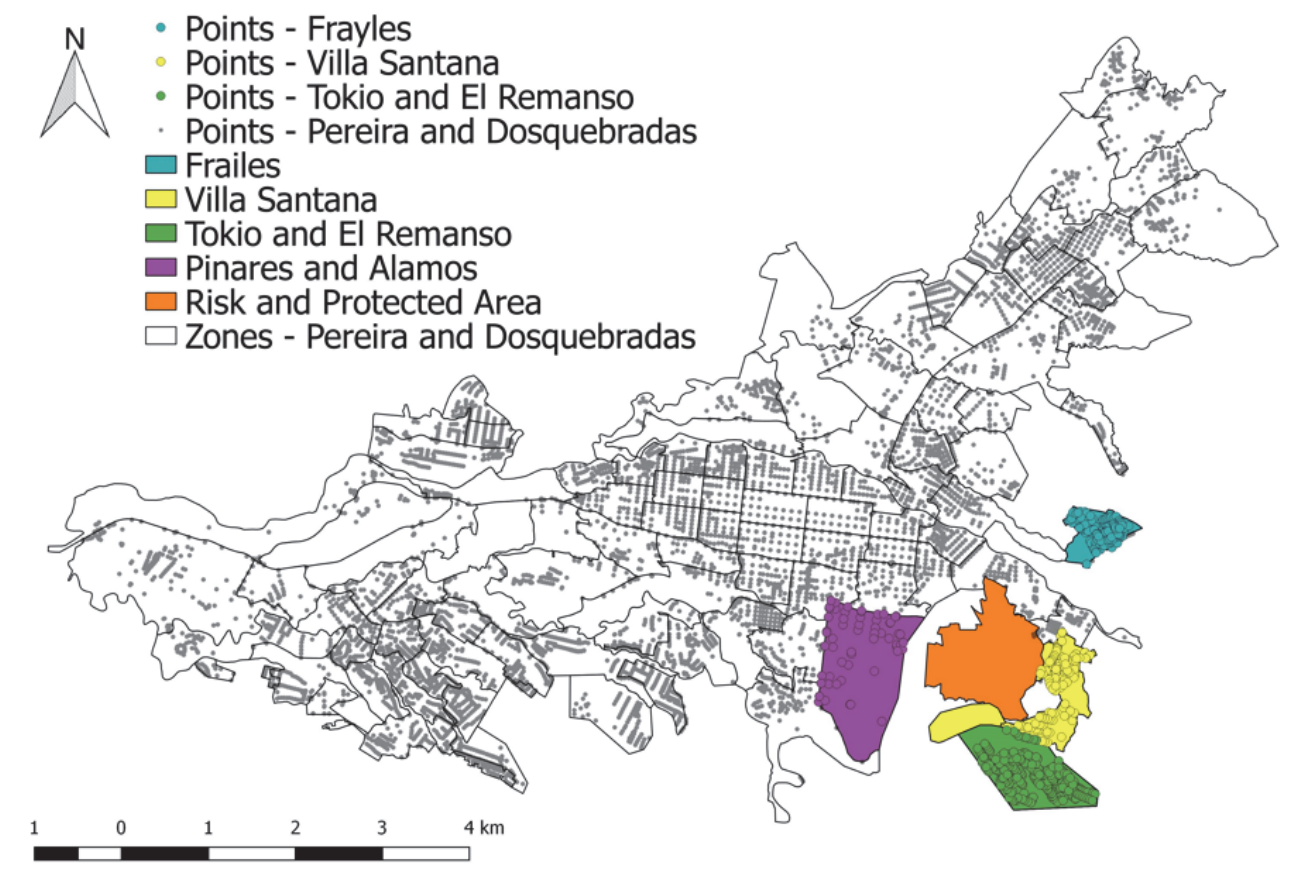

Figure 11. Frayles rural zone from Dosquebradas, Villa Santana, Tokio, El Remanso, Pinares and Alamos

Western area (branch 3 ) is the main difference between motorized (Figure 12a) and non-motorized modes (Figure 12b) because of the wider dispersion of nodes in non-motorized case. We interpret that as a result of hilly topography in that side of Pereira which means that in a flat environment MDS projections for motorized and nonmotorized transportation modes perform analogous but deviate in an elevated context. In fact, people in a car can travel at the same speed on a flat road than in a road with a high slope, it is only a matter of push the accelerate pedal and there is not any physical effort as in a bike or when walking.

San Joaquín communes' nodes, one of the biggest urban zones in Pereira and a fast house growing area, are plotted in MDS projection in a zone coherent with its geographic location (See Figure 13). MDS model suggest that deepest area has bad accessibility, points are established in periphery. Commune "Del Café" also known as "Parque Industrial" area is put away a little bit in motorized mode (See Figure 14a) but it is not as pronounced as in Nonmotorized mode (See Figure 14b). As mentioned above this is a consequence of topography (hilly environment). "Parque Industrial" is formed by low-income neighborhoods and, in a similar analysis to "Villa Santana", it has $35705.38 \mathrm{Km}$ (4.08\% of the total) of built streets but is not as efficient as Pinares and Alamos. This zone should also be considered for interventions focusing on move people to zones of the first and second quartiles of work generation illustrated in Figure 9.

Figures 15 show Samaria 1 and Samaria 2, Villa Verde and Miraflores neighborhoods, all make part of El Poblado commune. It can be seen that in non-motorized mode this area has bad accessibility, especially considering that 
geographically is not as far away as other zones of Pereira, mainly at the western of the city. These neighborhoods are clearly clustered (See Figure 16a and Figure 16b).

- MDS Projections - Frailes

- MDS Projections - Villa Santana

- MDS Projections - Tokio and El Remanso

- MDS Projections - Alamos and Pinares

MDS Projections - Pereira and Dosquebradas

- MDS Projections - Frailes

- MDS Projections - Villa Santana

- MDS Projections - Tokio and El Remanso

MDS Projections - Pereira and Dosquebradas

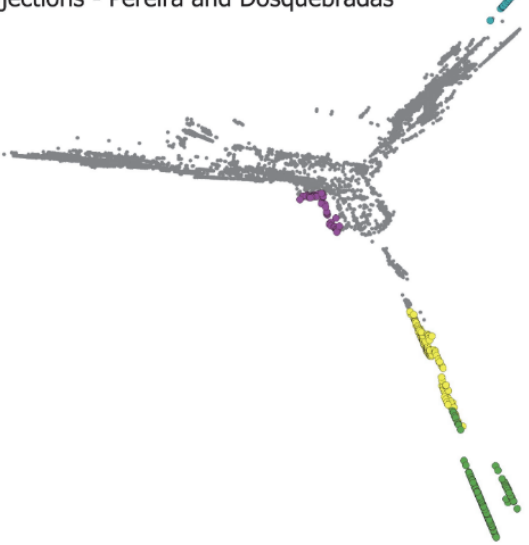

a)

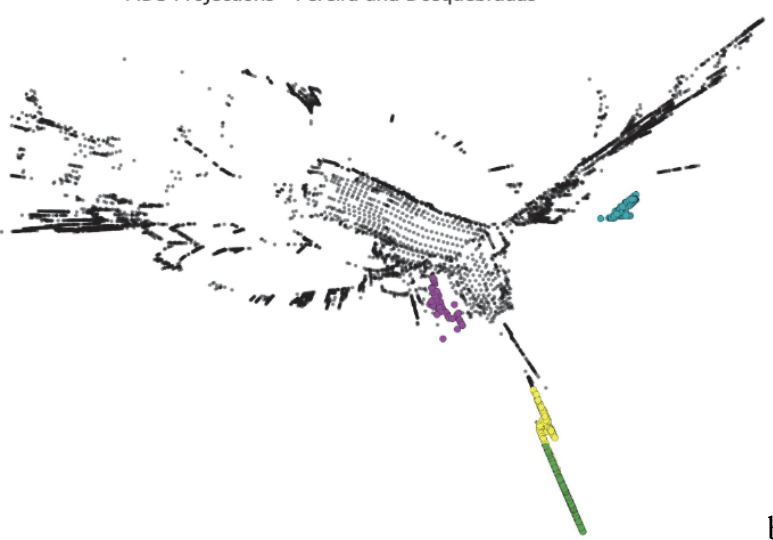

b)

Figure 12. Frayles rural zone from Dosquebradas, Villa Santana, Tokio, El Remanso, Pinares and Alamos, and MDS projections for transpot modes: a) motorized; b) non-motorized. Source: Authors' own.

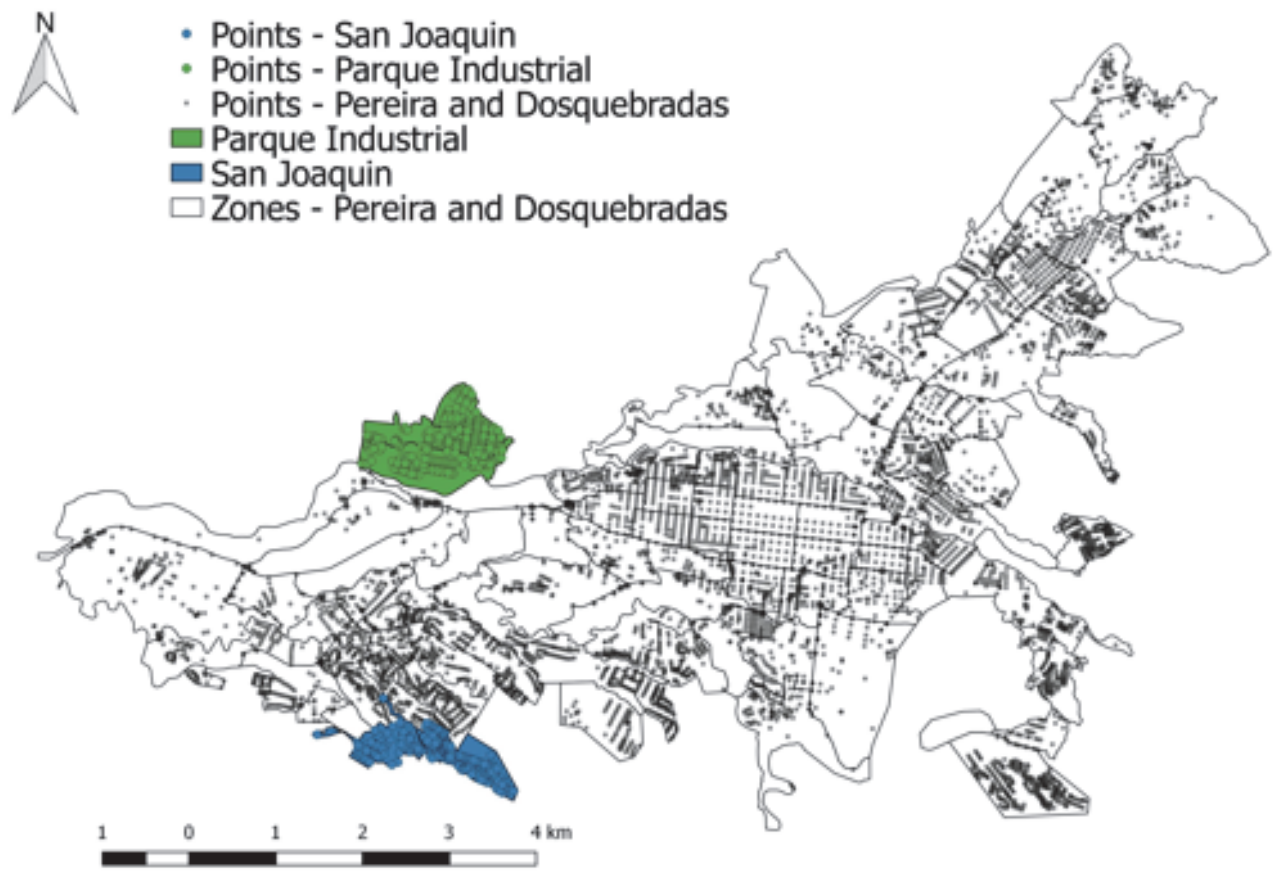

Figure 13. San Joaquin and Parque Industrial

The findings, as well as a detailed account of the proposed methodology was presented and discussed with local and metropolitan authorities in AMCO. The research team held several meetings and focus groups with selected decision makers, technical staff and non-specialist civil servants in the municipalities that were involved in transport and urban planning decisions. These participants were presented with general mathematical aspects related to MDS, and a quick guide to projections interpretation and the methodological aspects for data acquisition and processing. Participants involved claimed to easily understand results and obtained information they had not thought about before engaging with the MDS projections. Most participants agreed that one of the main applications of the methodology was to identify and analyze specific zones in the peripheral areas and those areas that despite appearing well-connected look segregated in the MDS projections, revealing limited connectivity with 
transport infrastructure facilities and recent public investment and social programs. Although the model proved to be useful within the limited scope of the analysis presented, some aspects highlighted by policy makers are not yet considered explicitly in the methodology. Such is the case of spatial separation to a set of opportunities like hospitals or schools and the relations between segregated zones and additional sociodemographic characteristics.
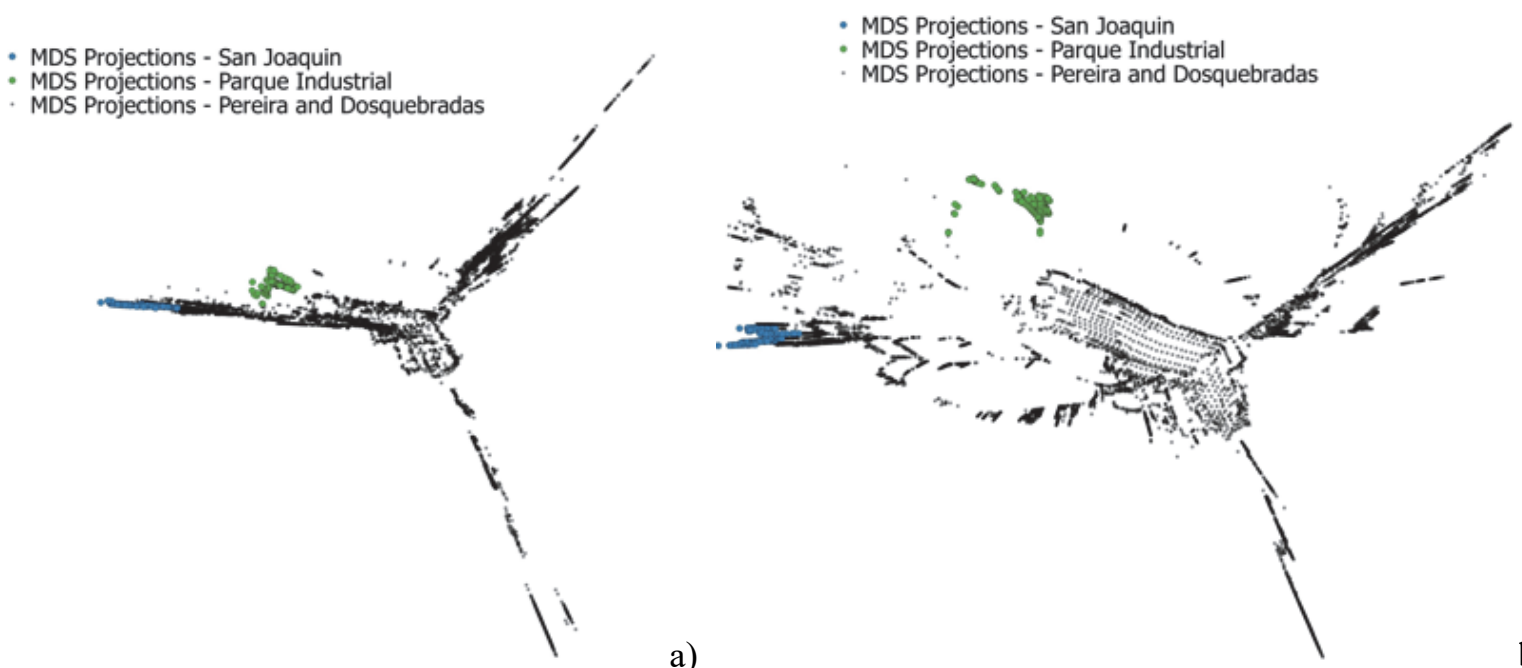

Figure 14. San Joaquin and Parque Industrial, and MDS projections for transpot modes: a) motorized; b) nonmotorized

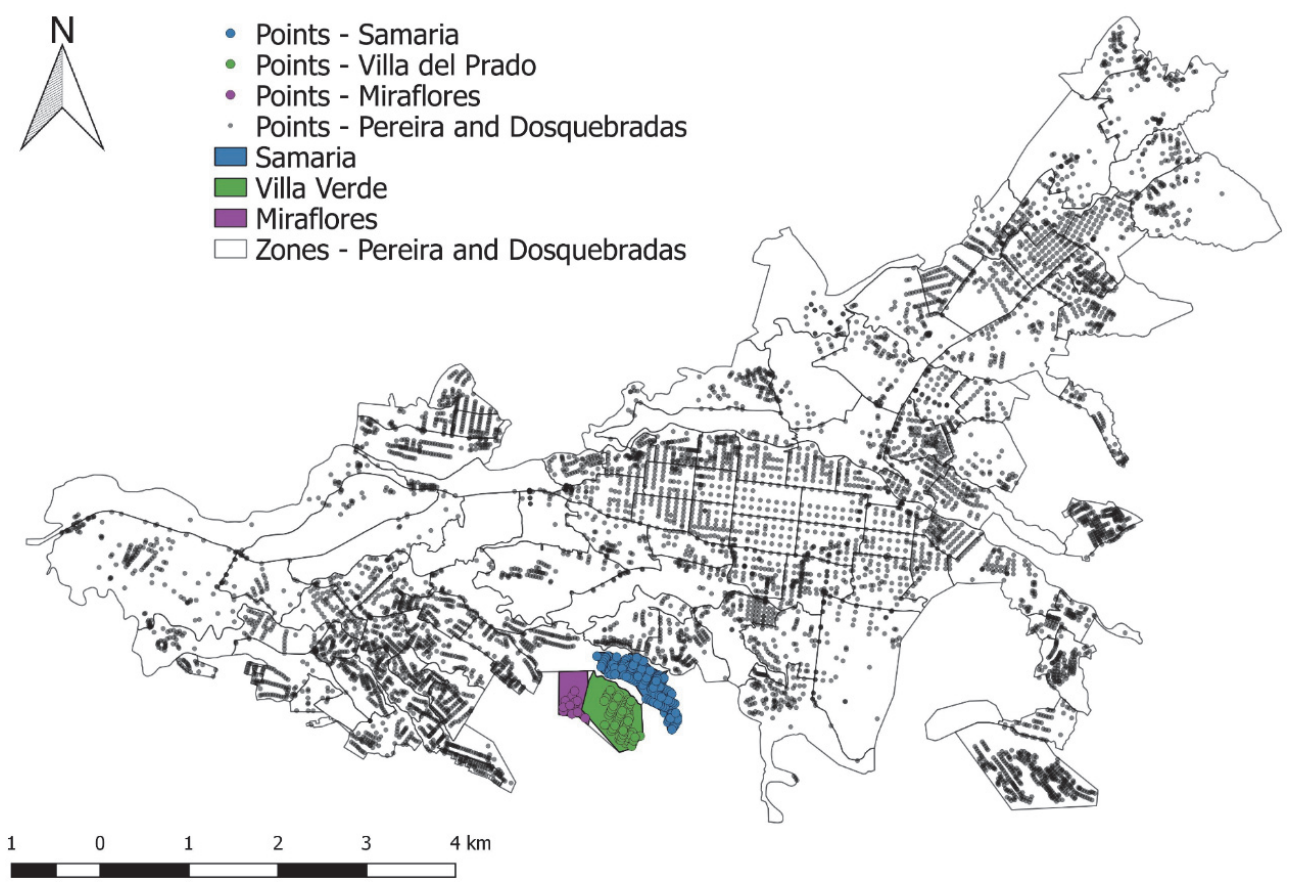

Figure 15. Samaria, Villa Verde and Miraflores

\section{Conclusions and Future Work}

We showcased multidimensional scaling model as a tool for exploring accessibility. Our approach plots projections of a road network's points based on travel-time matrices. Projections denote which points are the closest or furthest between them and when compared to original geographic locations, which enable a visual and intuitive tool to identify zones with accessibility problems, lack of connectivity or that are spatially segregated. Furthermore, it permits to explore the impact of the presence of geographic aspects such as mountains or rivers within an urban 
area. The proposed method plots projections of a road network based on travel-time matrices as proxy for accessibility. Other forms of accessibility metrics, such as potential accessibility measures, are yet to be tested. The method allows to combine different information with distance metrics, allowing to visually identify accessibility differences between socioeconomic groups, levels of attractiveness, and land-use characteristics. Other classifications variables will be explored in future research.

MDS Projections - Samaria

- MDS Projections - Villa Verde

- MDS Projections - Miraflores

MDS Projections - Pereira and Dosquebradas

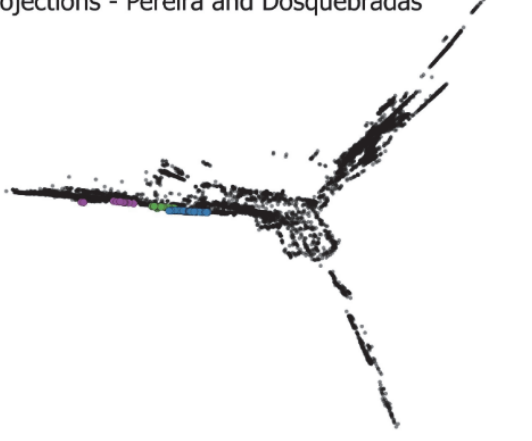

$i$
- MDS Projections - Samaria

- MDS Projections - Villa del Prado

- MDS Projections - Miraflores

- MDS Projections - Pereira and Dosquebradas

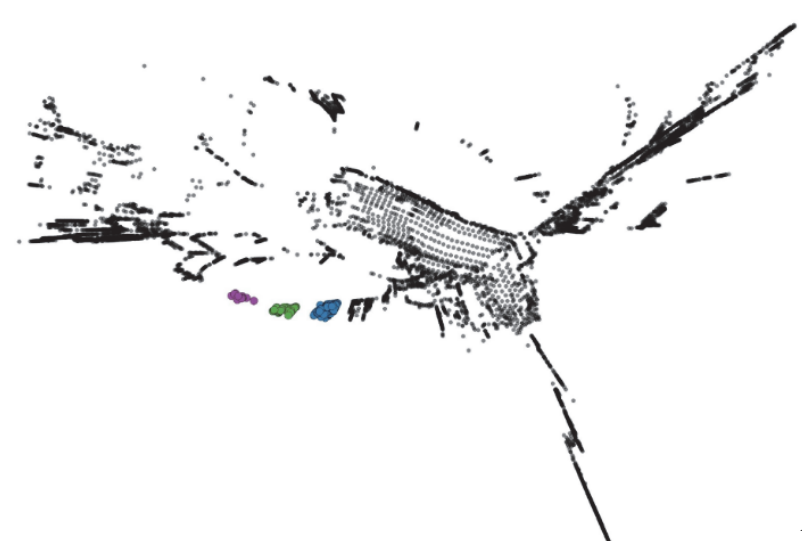

a)

Figure 16. Samaria, Villa Verde and Miraflores, and MDS projections for transport modes: a) motorized; b) nonmotorized

The model represents the case study in a spatial distribution through a central zone and three branches emerging from key connectivity facilities such as The Viaducto and Mosquera Bridge for Dosquebradas in branch one. Branches enlarge in a direction and narrow in the other one. The central area has the best accessibility levels and embraces high-income neighborhoods Pinares and Alamos while areas with the worst accessibility are in the corner branches. Motorized and non-motorized transportation modes are similar when geography is flat but diverge in hilly areas. Several segregated zones were found in the study area and are related to poverty, social exclusion and rural characteristics. Villa Santana commune, Frayles and San Joaquín demand special attention.

We consider that this work represents a starting point for using multidimensional scaling technique within accessibility frameworks and transport analysis, results and methodology aspects must be replicated in other cities of similar size or with larger road networks. If possible, data used should correspond to travel times collected using mobiles or geographic positioning system devices and perform analysis for different day times and compare a broad range of transport modes. Even though proposed framework enables a visual representation and understanding of accessibility, it is not yet clear how to analytically combine this kind of analysis with additional data; this could be one research path. Besides that, it is important to figure out how to link results from multidimensional scaling and socio demographic population characteristics, mainly how social inequality and land cost shapes excluded regions in projections.

The research intends to address topical challenges for transport planning in the Global South: availability of information, use of open-source tools in low-income/low-resources contexts (Oviedo, \& Dávila, 2016), and communication of technical information to a wider audience - Challenging "the monopoly of the expert" (Levy, 2013). The MDS approach produces an intuitive representation of accessibility that can contribute to improve communication between practitioners, decision-makers and the public. Empirical evidence from second-tier cities such as Pereira-Dosquebradas suggest the method may be replicable in cities of similar scale, often challenged by availability and reliability of data.

\section{Acknowledgments}

This work is part of the dissertation master research of one of the authors and it would have not been possible without the financial and academic support of Sirius Group at Technological University of Pereira, Colombia. 


\section{References}

Batty, M. (2009). Accessibility: In search of a unified theory. Environment and Planning B: Planning and Design, 36(2), 191-194. http://doi.org/10.1068/b3602ed

Borg, I., \& Groenen, P. J. (2005). Modern Multidimensional Scaling. New York, NY: Springer.

CAMACOL (2015). Informe de Ventas de Vivienda Nueva en Pereira, Risaralda. Retrieved from: http://www.camacolrisaralda.org/es/dominios/camacol.pagegear.co/upload/69/files/economico/informeventa s_dic2015pereira.pdf.

Escobar, D., \& García, F. (2012). Territorial Accessibility Analysis as a Key Variable for Diagnosis of Urban Mobility: A Case Study Manizales (Colombia). Procedia - Social and Behavioral Sciences, 48(0), 1385-1394. https://doi.org/10.1016/j.sbspro.2012.06.1114

Escobar, D., García, F., \& Cadena, C. (2013). Political determinants and impact analysis of using a cable system as a complement to an urban transport system. Proceedings of $1^{\text {st }}$ International Conference on Innovation and Sustainablity - ICOIS 2013. Redesigning Relationships for Government, Business and Community. Kuala Lumpur (Malaysia).

Escobar, D., García, F., \& Tolosa, R. (2013). Análisis de Accesibilidad Territorial a Nivel Regional. Universidad Nacional de Colombia. Facultad de Ingeniería y Arquitectura. ISBN 9789587612776, Manizales.

Everitt, B., \& Hothorn, T. (2011). An introduction to applied multivariate analysis with R. New York: Springer.

Geurs, K. T., \& Van Wee, B. (2004). Accessibility evaluation of land-use and transport strategies: review and research directions. Journal of Transport Geography, 12(2), 127-140. https://doi.org/10.1016/j.jtrangeo.2003.10.005

Goverment of Pereira. (2016). Plan de Ordenamiento Territorial 2016-2027. Secretaria de Planeación Municipal. Retrieved from http://www.pereira.gov.co/Transparencia/PlaneacionGestionyControl/Plan\%20de\%20Desarrollo\%2020162019.pdf

Gutiérrez, J., Condeco-Melhorado, A., \& Martín, J. (2010). Using Accessibility indicators and GIS to assess spatial spillovers of transport infraestructure investment. Journal of Transport Geography, 18, 141-152. http://dx.doi.org/10.1016/j.jtrangeo.2008.12.003

Halden, D. (2011). The use and abuse of accessibility measures in UK passenger transport planning. Transportation Business and Management, 2, 12-19. https://doi.org/10.1016/j.rtbm.2011.05.001

Hansen, W. G. (1959). How accessibility shapes land use. Journal of the American Institute of planners, 25(2), 73 76. https://doi.org/10.1080/01944365908978307

Jones, P., \& Lucas, K. (2012). The social consequences of transport decision-making: clarifying concepts, synthesising knowledge and assessing implications. Journal of transport Geography, 21, 4-16. https://doi.org/10.1016/j.jtrangeo.2012.01.012

Kotavaara, O., Antikainen, H., \& Rusanen, J. (2011). Population change and accessibility by road and rail networks: GIS and statistical approach to Finland 1970-2007. Journal of Transport Geography, 19(4), 926-935. https://doi.org/10.1016/j.jtrangeo.2010.10.013

Kruskal, J. B. (1964). Multidimensional scaling by optimizing goodness of fit to a nonmetric hypothesis. Psychometrika, 29(1), 1-27. https://doi.org/10.1007/BF02289565

Levy, C. (2013). Travel choice reframed: "deep distribution" and gender in urban transport. Environment Urbanization, 25(1), 47-63. https://doi.org/10.1177/0956247813477810

Lucas, K., Van Wee, B., \& Maat, K. (2015). A method to evaluate equitable accessibility: Combining ethical theories and accessibility-based approaches. Transportation, 43(3), 473-490. https://doi.org/10.1007/s11116015-9585-2

Martínez, L., \& Viegas, J. (2013). A new approach to modelling distance-decay functions for accessibility assessment in transport studies. Journal of Transport Geography, 26, 87-96. https://doi.org/10.1016/j.jtrangeo.2012.08.018

Morris, J. M., Dumble, P. L., \& Wigan, M. R. (1979). Accessibility indicators in transport planning. Transportation research part A: policy and practice, 13, 91-109. https://doi.org/10.1016/0191-2607(79)90012-8

Muñoz, R. (2010). Walking accessibility to bus rapid transit: Does it affect property values? The case of Bogotá, 
Colombia. Transport Policy, 17(2), 72-84. https://doi.org/10.1016/j.tranpol.2009.11.002.

Oviedo, D., \& Dávila, J. D. (2016). Transport, urban development and the peripheral poor in Colombia - Placing splintering urbanism in the context of transport networks. Journal of Transport Geography, 51, 180-192. http://dx.doi.org/10.1016/j.jtrangeo.2016.01.003

Páez, A., Scott, D. M., \& Morency, C. (2012). Measuring accessibility: positive and normative implementations of various accessibility indicators. Journal of Transport Geography, 25, 141-153. https://doi.org/10.1016/j.jtrangeo.2012.03.016

Pereira Cómo Vamos (2015). Encuesta de percepción ciudadana Pereira 2015. Retrieved from: http://www.pereiracomovamos.org/es/dominios/pcv.pagegear.co/upload/69/Publicaciones/1._folleto_encues ta_de_percepcion_ciudadana_2015_vf.pdf

Pérez, G. J., Valencia, F., González, B., \& Cardona, J. C. (2014). Pereira: Contexto actual y perspectivas. Documentos de trabajo sobre Economía Regional, 208, 1-63. http://www.banrep.gov.co/docum/Lectura_finanzas/pdf/dtser_208.pdf

Rencher, A. C. (2012). Methods of multivariate analysis. New Jersey: Wiley.

Stanley, J. K., Hensher, D. A., Stanley, J. R., \& Vella-Brodrick, D. (2011). Mobility, social exclusion and wellbeing: Exploring the links. Transportation research part A: policy and practice, 45(8), 789-801. https://doi.org/10.1016/j.tra.2011.06.007

Torgerson, W. S. (1958). Theory and Methods of Scaling. Wiley.

Van Wee, B. (2016). Accessible accessibility research challenges. Journal of Transport Geography, 51, 9-16. https://doi.org/10.1016/j.jtrangeo.2015.10.018

\section{Copyrights}

Copyright for this article is retained by the author(s), with first publication rights granted to the journal.

This is an open-access article distributed under the terms and conditions of the Creative Commons Attribution license (http://creativecommons.org/licenses/by/3.0/). 